\title{
Vein Biometric Recognition Methods and Systems: A Review
}

\author{
Ruaa S.S. Al-Khafaji ${ }^{*}$, Mohammed S.H. Al-Tamimi' \\ 1 Computer Science Department, College of Science, University of Baghdad, Baghdad, Iraq \\ * Corresponding author's e-mail: ruaa.salman1201@sc.uobaghdad.edu.iq
}

\begin{abstract}
The Finger-vein recognition (FVR) method has received increasing attention in recent years. It is a new method of personal identification and biometric technology that identifies individuals using unique finger-vein patterns, which is the first reliable and suitable area to be recognized. It was discovered for the first time with a home imaging system; it is characterized by high accuracy and high processing speed. Also, the presence of patterns of veins inside one's body makes it almost difficult to repeat and difficult to steal. Based on the increased focus on protecting privacy, that also produces vein biometrics safer alternatives without forgery, damage, or alteration over time. Fingerprint recognition is beneficial because it includes the use of low-cost, small devices which are difficult to counterfeit. This paper discusses preceding finger-vein recognition approaches systems with the methodologies taken from other researchers' work about image acquisition, pretreatment, vein extraction, and matching. It is reviewing the latest algorithms; continues to critically review the strengths and weaknesses of these methods, and it states the modern results following a key comparative analysis of methods.
\end{abstract}

Keywords: biometric technology, finger vein recognition, pre-processing, feature extraction, matching.

\section{INTRODUCTION}

Personal identifying technology has the shape of security schemes and its importance has grown in recent years, especially authentication manners, where passwords and magnetic cards are no longer secure enough, they can be stolen easily or be forgotten by the owner. Therefore, to reach a highly secure interaction, biometric technologies have been invented to apply to wide systems categories like smart devices logins and house securing systems, and other control systems [1]. Therefore, the issue of human identity recognition has become an important issue. Securing financial accounts from identity theft and providing the integrity of the existing systems can be accomplished by the automation control authentication systems to identify criminal acts, independent selling, automated banking, and more [2]. Biometrics is a mechanism that works on providing automatic verification for users relying on unique behavioral manners. Physiological features are inherited traits from embryonic stages of human development. As a newly emerging technology, vein-based biometrics technology was invented to recognize biometrics as an attractive technology when compared to traditional types like: (fingerprints, palm print, iris, and face). They can obtain the vein recognition method data sets at a low cost and in a simple manner as they are global dynamic processes [3]. This technology is immune against fraud or theft since the vein is in the body of man, is less prone to skin illness and diseases. This technology mainly uses manual vein, palm vein, and finger-vein [4]. It only takes a simple, cheap, and compact chip to recognize the actual user. What makes it attractive are the quick and cumulative results got from the identification process, unlike other methods such as fingerprints [3]. Whereas fingerprints have shown serious limitations with inaccurate results like degradation of finger skin, finger surface particles, etc. and Vein recognition systems view good and accurate results that can overcome the limitations of fingerprints, thanks to its unique characteristics such as (i) vein images are maintained unchangeable 
although human aging, (ii) hand and finger-vein discovery systems are not harmful to the user's general health, (iii) the state of the skin like (uneven tone and/or skin burns) does not change the outcomes of vein discovery, and (iv) The shapes of the vein are challenging to deceive and replace even with surgery $[5,6]$. The performance of the detector is widely related to the quality of the extraction of the venous figure and it has an immediate influence on feature extraction and matching standards. The process is about acquiring the image of finger-vein by implementing near-infrared spectroscopy at a wavelength of $760 \mathrm{~nm}$. When it is placed near this wave, the vein designs are caught. The greatest difficulty with the Biometric system optimizes the Reconnaissance process [7].

\section{SECURITY BIOMETRIC}

Security is enhanced by biometric systems. One of the most important advantages of biometric security devices is that they may help you improve your security. Cloning or stealing a fingerprint, for example, is significantly more difficult than cloning or stealing an access card. Biometrics can also be utilized for multifactor verification in instances where security is a concern, and the next Table 1 shows the fames technique used in security [8].

\section{FINGER VEIN RECOGNITION CONCEPT}

Finger vein biometrics is rapidly establishing itself as the most secure means of automated personal identification. The finger vein is a unique physiological biometric that allows for the identification of people based on the physical traits and properties of the vein patterns in the human finger. It is a relatively new technological advancement in the field of biometrics that is being used in a variety of industries including healthcare, finance, law enforcement, and other applications that need a high level of confidentiality or privacy. This technique is amazing since it needs a compact, reasonably inexpensive single-chip design and has a very quick identification procedure that is contactless and more accurate than other biometric identification methods such as fingerprint, iris, or face. This increased accuracy is not unrelated to the fact that finger vein patterns are extremely hard to counterfeit. As a result, it has become one of the fastest developing new biometric technologies, rapidly moving from research laboratories to commercial development. Historically, Hitachi's R\&D department established that finger vein pattern recognition was a feasible biometric for personal identification technology in 1997-2000 and was the first to commercialize the technology in various product forms, such as ATMs, between 2000 and 2005 [9].

\section{FINGER-VEIN RECOGNITION DEVICE}

Veins locating techniques have been introduced by the medical center in Japan. Since then, these techniques have gained popularity and many countries have developed different vein recognition systems $[2,10]$. These systems implement many features on different human body veins like palm, foot, manual, and Nigerian vein. The finger vein, on the other hand, is the most preferred one because it only requires small and simple tools than other veins [11]. The uniqueness of the vein extends to being different even for identical twins, also remains unchangeable during human life. More importantly, each vein of yoke does not change during life. The Fingerprint Vein Recognition Device idea is simple. It only requires the following: (i) Image capture unit, (ii) Digital Special Processing (DSP) board, and (iii) Human automated communication unit [12]. The image acquisition unit is used to extract vein pictures from the fingers, and the DSP board is equipped

Table 1. Various biometric traits $[7,8]$

\begin{tabular}{|c|c|c|c|c|c|c|c|c|}
\hline Technique & $\begin{array}{l}\text { Security } \\
\text { level }\end{array}$ & Cost & Sensor & Pros. & Cons. & $\begin{array}{l}\text { Size of } \\
\text { template }\end{array}$ & $\begin{array}{l}\text { Long term } \\
\text { stability }\end{array}$ & $\begin{array}{l}\text { Accuracy } \\
\text { (ACC) }\end{array}$ \\
\hline Face & Normal & Low & Non-contact & $\begin{array}{c}\text { Captured from a } \\
\text { remote area }\end{array}$ & $\begin{array}{l}\text { Lighting } \\
\text { conditions }\end{array}$ & Large & Low & Medium \\
\hline Voice & Normal & Low & Non-contact & Natural \& convenient & Noisy & Small & Low & Low \\
\hline Iris scan & Medium & High & Non-contact & High accuracy & Glasses & Small & Medium & High \\
\hline Fingerprint & Good & Low & Contact & Greatly applied & Skin & $\begin{array}{l}\text { Small } \\
\text { size }\end{array}$ & Bottom & High \\
\hline Finger vein & Higher & Middle & Non-contact & High-security level & Disease & Middle & High & High \\
\hline
\end{tabular}




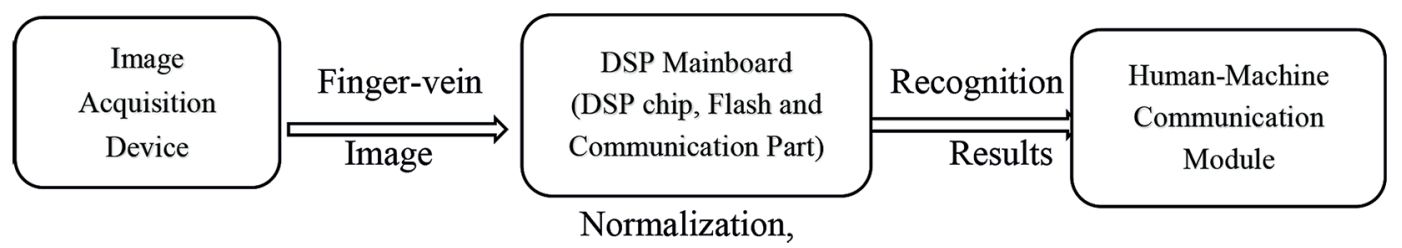

Fig. 1. Hardware systems diagram [13]

with (memory, a chip, and a communication port to compromise the implanted). Finally, a human automated communication unit is constructed to examine the extracted findings. This unit is composed of Light Emitting Diodes (LEDs) and/or a keyboard [13]. Figure 1 shows the structure diagram of the finger vein recognition system.

In general, finger-vein recognition algorithms have two main steps: (i) registration and verification Both start with a pre-finger-vein image that requires the following: (1) detection of the targeted which region is the Region of Interest (ROI), (2) align Illustration and segment it, and (3) optimization. The registration stage creates the database necessary for storing the extracted pictures, and the verification step pairs the input image with a comparable pattern after exporting its attributes [14]. The method depicted in Figure 2 is one in which near-infrared rays created by a sequence of LEDs enter the finger and are absorbed by the hemoglobin, with the finger contained within the Infrared Light Emitting Diodes (IR-LEDs) and the identification engine.

\section{IMAGE DEVICE}

Special hardware has been developed to gain a high-quality Near-Infra Red (NIR) image, to extract vein images without being affected by ambient temperature. Three methods are implemented to create a finger-vein picture: (i) "lighttransmission method" (ii) "a light-reflection method", and (iii) "a method for multi-way radiation method" [13]. The Transmission method gives a sharp variation image, therefore it is the most implemented method; the main variation within transition and reflections methods is that the location of NIR and Charge Coupled Device (CCD) camera [15]. There are some challenges facing image extracting like noise and it is important to get high-quality results in this step, but it is impossible to implement enhancement methods during image acquisition. Therefore, pre-processing steps are invented to overcome the challenges [16].

\section{STEPS OF FINGER-VEIN RECOGNITION}

The recognition system contains three processes as the following: (i) pre-processing the image, (ii) extracting the features, and (iii) matching methods there are three types of recognition systems known as a conventional method, machine learning, and mixing machine learning with conventional methods. Some of these methods require preprocessing set steps to improve the picture quality [17]. Figure 3 views the diagram of the recognition system.

\section{IMAGE DEVICE}

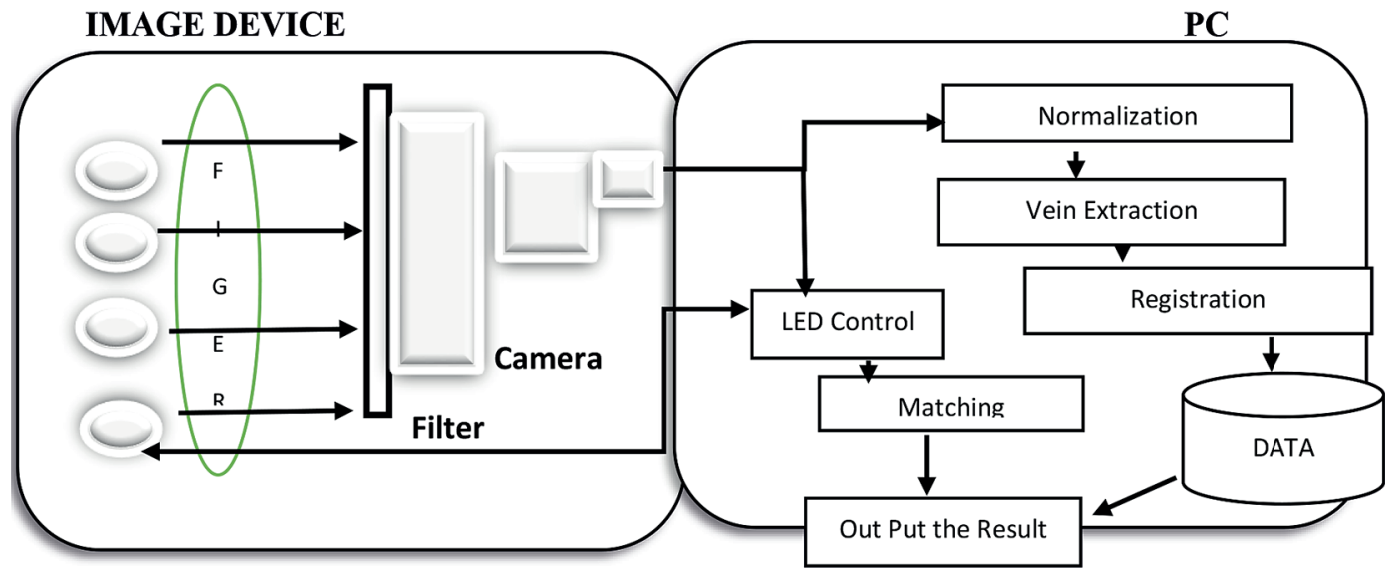

Fig. 2. Extraction function of finger-vein patterns [14] 


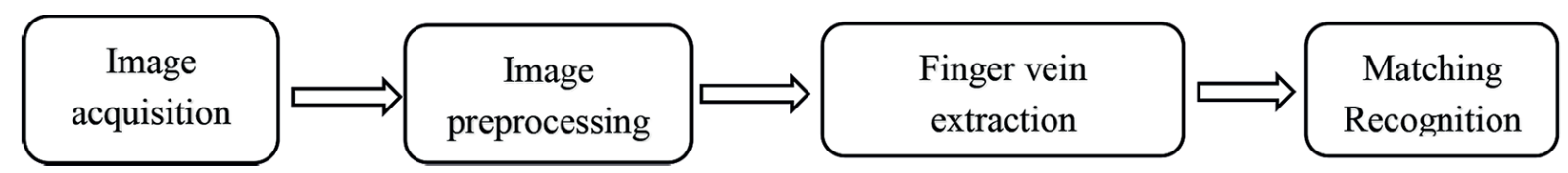

Fig. 3. Block diagram of digit-vein recognition system [17]

\section{Image acquisition step}

The acquisition includes NIR modeling of the finger's position, as well as the CCD utilized to capture the picture of the finger vein. While infrared light may pass through a finger, hemoglobin is more efficient at absorbing light than other substances such as muscles and bones [18].

\section{Pre-processing step}

As previously stated, pre-processing processes are critical for overcoming picture quality issues. Three phases comprise the recognition procedure [19]. (i) "Pre-processing", (ii) "Feature extraction," and (iii) "Classification". The challenges that are facing the extracted images, especially the smaller ones, are noise, low contrast, and ghosting. These challenges depend mainly on the quality of the device. Some works have implemented the pre-processing step as an optimization option for the gained image. After this step, the output image gets a higher quality as the performance of the system by improving the contrast and the brightness at the same time reducing the noise [20]. Un-matching light usually arises because of the specific variations in the size of the finger or lighting positions. should just select the vein features from the unstable image. The accuracy of the identification process depends heavily on the pre-processing step which contains a set of operations like ROI detection, image enhancement, segmentation, and filtering [21].

\section{Feature-vein extraction step}

The vein can be recognized in a variety of ways based on the criteria used to extract the features. In essence, all of these techniques fall into three categories: dimension reduction, local binomial, and vein-based. Several algorithms have been produced to contribute to enhancing this step. This step could be split into two categories: (i) threshold algorithm and (ii) hash algorithm based on image content [18]. There are many methods to extract vein features based on dimensions, style, and local two-way, which are predominant, in finger-vein extraction. The geometrical and topological structure of the extracted vein pattern is utilized to match between translation and rotation of pixels [17]. Figure 4 illustrated how to extract the final-vein-image.

Table 2 summarizes a study to compare the feature extraction methods of the three methods that implement vein recognition along with the results obtained.

\section{Matching step}

It is the final step where it is utilized to make a comparison of the input image and the saved image to ensure whether they are belonging to the same person where the results are shown after the matching process when measuring conformity between the images [31]. There are two matching types methods (i) distance-based (ii) matching classics [32]. Minor veins matching uses a distance-based method while machine learning algorithms like fuzzy logic, "Natural Language

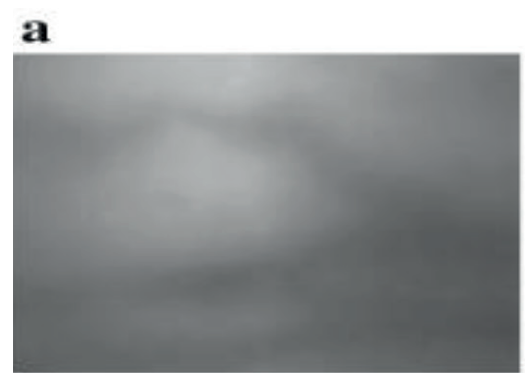

b

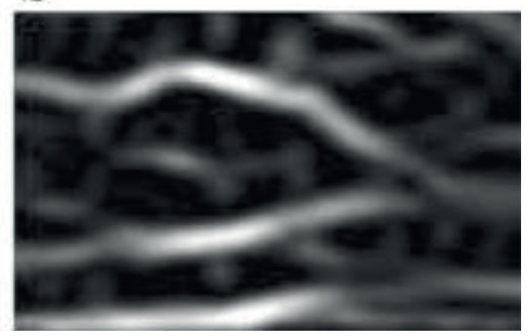

Fig. 4. Extraction of the vein pattern on the finger; a) Original image b) Map of vein patterns [23] 
Table 2. Feature extraction methods

\begin{tabular}{|c|c|c|c|c|}
\hline References & Approach & Category & Advantage & Disadvantage \\
\hline $\begin{array}{c}2010 \\
{[24]}\end{array}$ & Manifold Learning & \multirow[b]{2}{*}{$\begin{array}{l}\text { Dimensionality } \\
\text { Reduction Based }\end{array}$} & \multirow[b]{2}{*}{$\begin{array}{l}\text { This approach has the ben- } \\
\text { efit of a high recognition rate } \\
\text { due to the feature's small } \\
\text { dimensions, a reduction that } \\
\text { changes the picture from a } \\
\text { higher to a smaller dimension. }\end{array}$} & $\begin{array}{l}\text { Low recognition rate, } \\
\text { insufficiency of robustness }\end{array}$ \\
\hline $\begin{array}{c}2012 \\
{[25]}\end{array}$ & $\begin{array}{l}\text { Principal Component } \\
\text { Analysis (PCA) }\end{array}$ & & & $\begin{array}{l}\text { Global features are highly } \\
\text { dependent on parameters like } \\
\text { location, occlusion, distortion, } \\
\text { and lighting and are hence } \\
\text { unsuitable for extraction } \\
\text { as vein finger features. }\end{array}$ \\
\hline $\begin{array}{l}2011 \\
{[26]}\end{array}$ & $\begin{array}{l}\text { Local Line Binary } \\
\text { Pattern (LLBP) }\end{array}$ & \multirow{3}{*}{$\begin{array}{l}\text { Local Binary- } \\
\text { Based Method }\end{array}$} & $\begin{array}{l}\text { Numerous characteristics; } \\
\text { a minimal correlation }\end{array}$ & \multirow{2}{*}{$\begin{array}{l}\text { Numerous computations, } \\
\text { time-consuming }\end{array}$} \\
\hline $\begin{array}{c}2012 \\
{[27]}\end{array}$ & $\begin{array}{l}\text { Location and Direction } \\
\text { Coding (LDC) }\end{array}$ & & $\begin{array}{l}\text { between characteristics; } \\
\text { high robustness }\end{array}$ & \\
\hline $\begin{array}{l}2019 \\
{[28]}\end{array}$ & $\begin{array}{c}\text { Weber Local } \\
\text { Descriptors (WLD) }\end{array}$ & & $\begin{array}{c}\text { Powerful discrimination; } \\
\text { sturdiness and effectiveness }\end{array}$ & $\begin{array}{l}\text { The features of the line are of } \\
\text { a slightly higher dimension. }\end{array}$ \\
\hline $\begin{array}{r}2011 \\
{[29]}\end{array}$ & Mean Curvature (MC) & \multirow{2}{*}{$\begin{array}{l}\text { Vein Pattern } \\
\text { Based }\end{array}$} & $\begin{array}{l}\text { Insensitive to the unequal } \\
\text { vein width, as well as the } \\
\text { extraction of core venous sites. }\end{array}$ & $\begin{array}{l}\text { Some pixels are not } \\
\text { tuned correctly }\end{array}$ \\
\hline $\begin{array}{r}2011 \\
{[30]}\end{array}$ & Gabor Filtering & & $\begin{array}{l}\text { Improve image quality; enhance } \\
\text { recognition performance }\end{array}$ & Low robustness \\
\hline
\end{tabular}

Processing (NLP)", "Artificial Neural Networks (ANNs)" use classic (traditional) methods and they are stronger against noisy data. In addition, these methods are systematically adaptive and have a parallel mathematical structure. Many researchers have implemented classification-based matching with vein recognition systems [33], and many finger-vein templates exist to reduce the changes during the matching process [34]. There are two major challenges facing the identification process and enhancing the verification: (i) extracting robust vein-features even within a noisy environment and (ii) optimizing system efficiency to achieve high-quality matching [35]. Additionally, the database might have an effect on the extraction process and the system's performance [36]. The conventional finger-vein recognition method has become very popular in recent years. The researchers have developed a fingervein verification approach with very high-performance rates [24], as well, it achieved a minimum error rate after the recognition with different datasets [37]. However, the computational cost remains high [38]. This method is less robust in a noisy environment than other methods [39]. As a result, it necessitates additional processes prior to the final findings, such as pre-processing procedures used before feature extraction and matching. Table 3 summarizes the finger vein recognition approaches. Machine learning has been used extensively in biometric feature extraction and phase matching. Using these types of techniques, feature extraction, matching, and FVR method improvement have been proven to be useful in extracting features, matching, and enhancing the performance of machine learning that is based on learning representations of data. Machine learning techniques can be classified as supervised or unsupervised. Because supervised machine learning approaches train classification models using pictures with their ground truth labels, we apply $\mathrm{k}$-nearest neighbor $(\mathrm{k}-\mathrm{NN})$, support vector machine (SVM), artificial neural network (ANN), and fuzzy algorithms. Segmentation is conducted using unsupervised algorithms such as gaussian mixture models (GMM), fuzzy c-means (FCM), and k-means clustering [15]. Deep learning technologies for finger-vein recognition are very powerful in the case of direct learning from raw pixels without any directions; this powerfulness increases the accuracy, which makes it very attractive. Multiple layers in deep learning algorithms help to learn representation/hierarchical features from datasets [33]. They were successfully applied to assess finger vein image quality and achieved high accuracy in determining quality while assessing current conventional image quality. Although there is a lack of providing a dataset for small-vein recognition, the accuracy is remarkable [40]. Deep Convolutional Neural Networks (DCNNs) were proposed with a challenging mining and validation method that performed with better results than commercial vein validation methods [41]. They have proposed to overcome the lack of storage space issues by reducing the template size, which eventually will reach a faster 
Table 3. Shows approach to finger vein recognition methods with their respective scales

\begin{tabular}{|c|c|c|c|}
\hline References & Method & Disadvantages & Matching \\
\hline $\begin{array}{l}\text { Vega A.P } \\
\text { et al., } 2014[43]\end{array}$ & $\begin{array}{l}\text { Collaborative feature extraction and } \\
\text { cross-correlation matching using } \\
\text { Personalized Best Bit Maps (PBBM) }\end{array}$ & $\begin{array}{l}\text { A reduction in the energy efficiency threshold } \\
\text { value and a reduction in the value of the } \\
\text { threshold value are both necessary }\end{array}$ & \multirow{3}{*}{$\begin{array}{l}\text { Conventional } \\
\text { recognition }\end{array}$} \\
\hline $\begin{array}{l}\text { Vlachos M. and } \\
\text { Dermatas E. } \\
2015[44]\end{array}$ & $\begin{array}{l}\text { Morphological expansion and filtering } \\
\text { with thresholding of entropy for } \\
\text { and matching of the template }\end{array}$ & $\begin{array}{l}\text { Misalignment, finger vein darkening, and } \\
\text { darkening of the finger veins all influence } \\
\text { recognition performance }\end{array}$ & \\
\hline $\begin{array}{l}\text { Liu H. et al., } 2017 \\
{[45]}\end{array}$ & $\begin{array}{l}\text { Gray and size normalization with ROI } \\
\text { extraction, } \\
\text { Customized Local Line Binary Pattern } \\
\text { (CLLBP) and matching score }\end{array}$ & $\begin{array}{l}\text { Since it only deals with the acquisition } \\
\text { system's image improvement direction, it } \\
\text { needs to be central to this plan }\end{array}$ & \\
\hline $\begin{array}{l}\text { Park and Kang } \\
\text { Ryoung, } \\
2011[46]\end{array}$ & $\begin{array}{l}\text { Local Binary Pattern (LBP) } \\
\text { and SVM for matching }\end{array}$ & $\begin{array}{l}\text { The information must be decreased to } \\
\text { eliminate point characteristics such as } \\
\text { bifurcation and the ends of finger vein lines, } \\
\text { as well as to expand the data set to include } \\
\text { more ages, genders, and vocations }\end{array}$ & \multirow{7}{*}{$\begin{array}{l}\text { Machine } \\
\text { learning }\end{array}$} \\
\hline $\begin{array}{l}\text { Wu and Liu, } \\
2011[47]\end{array}$ & $\begin{array}{l}\text { PCA and Linear Discriminant Analysis } \\
\text { (LDA), as well as matching through } \\
\text { SVM and an Adaptive Neuro Fuzzy } \\
\text { Inference System (ANFIS) }\end{array}$ & $\begin{array}{l}\text { It only works in an environment with } \\
\text { controlled background noise, some } \\
\text { images are damaged due to poor lighting, } \\
\text { observation angle, and other parameters }\end{array}$ & \\
\hline $\begin{array}{l}\text { Wang et al., } 2012 \\
\text { [21] }\end{array}$ & $\begin{array}{l}\text { A variance of local binary patterns } \\
\text { (LBPV), Gaussian filter, and Global } \\
\text { Matching SVM }\end{array}$ & $\begin{array}{l}\text { To compute the SVM, each input data } \\
\text { set requires its own technique of feature } \\
\text { extraction and dimension reduction }\end{array}$ & \\
\hline $\begin{array}{l}\text { Khellat-kihel S. } \\
\text { et al., } 2014 \text { [15] }\end{array}$ & $\begin{array}{l}\text { Information capacity, a gradient in the } \\
\text { spatial domain, entropy with Image } \\
\text { contrast and } \\
\text { Gabor feature and matching by } \\
\text { Support Vector Regression (SVR) }\end{array}$ & $\begin{array}{l}\text { Focus on integrating and creating an } \mathrm{ROI} \text { in } \\
\text { the venous system. } \\
\text { A multimodal scheme as many biometric } \\
\text { systems }\end{array}$ & \\
\hline $\begin{array}{l}\text { Veluchamy S. and } \\
\text { L. Karlmarx R., } \\
2016 \text { [48] }\end{array}$ & $\begin{array}{l}\text { Location on a grid, feature-level } \\
\text { fusion by Fractional Firefly (FFF) and } \\
\text { matching by K-Means Support Vector } \\
\text { Regression (K-SVM) }\end{array}$ & $\begin{array}{l}\text { Various objective functions are required to be } \\
\text { developed to find the ideal weight score and } \\
\text { to improve results }\end{array}$ & \\
\hline $\begin{array}{l}\text { Khanam R. et al., } \\
2019 \text { [49] }\end{array}$ & Discriminant Analysis (DA) and k-NN & Low robustness and not using all data set & \\
\hline $\begin{array}{l}\text { Ng Tze Han et al., } \\
2021[50]\end{array}$ & $\begin{array}{l}\text { Adaptive K-nearest Centroid Neighbor } \\
\text { (Ak-NCN) }\end{array}$ & $\begin{array}{l}\text { Not using data set for two sessions, but one } \\
\text { session from data }\end{array}$ & \\
\hline $\begin{array}{l}\text { Qin H. et al., } \\
2017 \text { [51] }\end{array}$ & Fully Convolutional Network (FCN) & $\begin{array}{l}\text { Much more remains to be done to improve } \\
\text { verification accuracy }\end{array}$ & \multirow{6}{*}{ Deep learning } \\
\hline $\begin{array}{l}\text { Huafeng Qin and } \\
\text { Mounim, } \\
2017 \text { [52] }\end{array}$ & $\begin{array}{l}\text { Extraction and patching of gabor } \\
\text { features - Deep Neural Network } \\
\text { (DNN)+ Probabilistic Support Vector } \\
\text { Machines (P-SVM) }\end{array}$ & $\begin{array}{l}\text { Not to use representative learning in } \\
\text { other stages of biometrics of finger veins, } \\
\text { i.e., background vein segmentation and } \\
\text { verification }\end{array}$ & \\
\hline $\begin{array}{l}\text { Das R. } \\
\text { et al., } 2018 \text { [53] }\end{array}$ & $\begin{array}{l}\text { Five convolutional layers, three max- } \\
\text { pooling layers, one SoftMax layer, and } \\
\text { one ReLu layer with contrast-limited } \\
\text { adaptive histogram equalization make } \\
\text { up the Convolutional Neural Network } \\
\text { (CNN) Model (CLAH) }\end{array}$ & $\begin{array}{l}\text { Cannot be used on photos of non-trained } \\
\text { classes' finger veins. }\end{array}$ & \\
\hline $\begin{array}{l}\text { Avc A. et al., } \\
2019 \text { [54] }\end{array}$ & 4 CNN model & $\begin{array}{l}\text { Data augmentation may be used to enhance } \\
\text { training samples for four datasets using } \\
\text { non-publicly available data to reduce over- } \\
\text { customization of the CNN designs. }\end{array}$ & \\
\hline $\begin{array}{l}\text { Boukari S. et al., } \\
2020[55]\end{array}$ & CNN and k-NN & $\begin{array}{l}\text { Results need to be improved because } \\
\text { grading takes a long time }\end{array}$ & \\
\hline $\begin{array}{l}\text { Zhao et al., } \\
2020 \text { [56] }\end{array}$ & $\begin{array}{l}\text { Three convolutional layers, three max- } \\
\text { pooling layers, and two fully linked } \\
\text { layers comprise the CNN model (FCL) }\end{array}$ & $\begin{array}{l}\text { The suggested system is not robust, and you } \\
\text { should improve the performance accuracy. } \\
\text { Second, the details of this model should be } \\
\text { enhanced and supplemented with the loss } \\
\text { function in trials to enable comparison of } \\
\text { comparable performance and study of the } \\
\text { benefits and drawbacks of each loss function }\end{array}$ & \\
\hline
\end{tabular}


matching process rather than traditional methods that rewire additional steps and more processing time and effort. Many researchers suggested a robust DCNNs model to overcome the problem of alignment and vignetting and to lessen the complexity of pre-processing and feature extraction steps [40]. Recommended a powerful and DCNNs model to conquer the issue of arrangement and vignetting. It likewise decreases the time and exertion required for pre-preparing and highlight extraction, which lessens the computational expense of highlight extraction [42]. A profound learning impact doesn't need confounded handling and image preparing. Besides, profound learning strategies are hearty in confronting issues of clamor and inconsistency [33].

\section{DATASET}

Datasets are an important component of any vein recognition system. It comprises images obtained from different individuals with the help of some scanners. Venous biometric data includes images of the finger-veins. However, the technology implemented in the production of vein capture devices has not been standardized because this field is new and has not been discussed in great detail. Each scanner has different specifications and results with different image quality. It can generate artificial venous patterns instead of getting them from people. These artificial vein images are used to train and test different biometrics systems [3]. Lack of dataset availability will lead to a lack of performance measures; many universities provide free access to different datasets in the field of FVR for researchers. However, the provided datasets were not perfectly organized in most cases. For example, these databases may contain only finger vein images or simply finger texture photos, with no reference to the users' gender, blood type, skin color, or nationality. All of this information is crucial and can have a significant impact on the device's functionality. There are several publicly available knowledge bases on five-finger veins, which are included in Table 4 . These databases were created uniquely through the use of diverse photographs, the number of fingers, the structure of the images, and so on [57].

\section{THE MOST IMPOTENT STUDIES COMPARE}

The following Table 5. Presents the most important recent studies to identify the finger vein and display the percentages of accuracy (ACC) and error (ERR) in it for different datasets from 2015 to 2021.

\section{CONCLUSION}

This review article summarizes several current studies on the recognition of the finger vein, in which researchers evaluated the merits and disadvantages of the various methodologies employed in biometric identification systems and detailed the methodology. In particular, the steps used to obtain images were reduced and how to evaluate

Table 4. Public finger-vein databases

\begin{tabular}{|c|c|c|c|c|c|c|}
\hline Reference & No. image & $\begin{array}{l}\text { No. of } \\
\text { Sample }\end{array}$ & No. of finger per sample & $\begin{array}{l}\text { No. of } \\
\text { image per } \\
\text { finger }\end{array}$ & $\begin{array}{l}\text { Resolution } \\
\text { (pixel) }\end{array}$ & Owner \\
\hline PKU, 2010, [58] & 50,700 & 5,208 & 10,140 & 5 & $512 \times 384$ & Peking University \\
\hline $\begin{array}{l}\text { HKPU-FV, 2011, } \\
{[30]}\end{array}$ & 3744 & 156 & $\begin{array}{l}2 \text { (Left-hand index \& } \\
\text { middle finger) }\end{array}$ & 12 & $513 \times 256$ & $\begin{array}{l}\text { Hong Kong Polytechnic } \\
\text { University Campus }\end{array}$ \\
\hline $\begin{array}{l}\text { THU-FVFDT, } \\
\text { 2012, [59] }\end{array}$ & 880 & 220 & 1 & 4 & $720 \times 576$ & Tsinghua University \\
\hline $\begin{array}{c}\text { FV-USM, 2014, } \\
{[60]}\end{array}$ & 5904 & 123 & $\begin{array}{l}12 \text { (Left \& right-hand } \\
\text { index \& middle finger) }\end{array}$ & 4 & $640 \times 480$ & $\begin{array}{c}\text { Sains } \\
\text { Malaysia }\end{array}$ \\
\hline UTFV, 2013, [61] & 1440 & 60 & \multirow{3}{*}{$\begin{array}{l}6 \text { (Index, the ring area, } \\
\text { and the middle area) for } \\
\text { both hands }\end{array}$} & 4 & $672 \times 380$ & $\begin{array}{l}\text { University of Twente by } \\
\text { completing }\end{array}$ \\
\hline $\begin{array}{l}\text { MMCBNU_6000, } \\
\text { 2013, [57] }\end{array}$ & 6000 & 100 & & 10 & $480 \times 640$ & $\begin{array}{l}\text { The Chonbuk University } \\
\text { in South Korea }\end{array}$ \\
\hline $\begin{array}{l}\text { SDMULA-HMT, } \\
2011 \text { [62] }\end{array}$ & 3816 & 106 & & 6 & $320 \times 240$ & $\begin{array}{l}\text { The Shandong } \\
\text { University of China }\end{array}$ \\
\hline UTFVP, 2014, [63] & 1440 & 60 & 4 & 6 & $672 \times 380$ & University of Twente \\
\hline
\end{tabular}


Table 5. Comparing the most important studies with the results

\begin{tabular}{|c|c|c|c|c|c|c|}
\hline Reference & Method & Dataset & $\begin{array}{l}\text { Number } \\
\text { of images } \\
\text { from } \\
\text { dataset }\end{array}$ & Final result & Advantage & Disadvantage \\
\hline $\begin{array}{l}2015 \\
\text { Ardianto W. } \\
\text { et.al., [64] }\end{array}$ & $\begin{array}{l}\text { Local Hybrid } \\
\text { Binary Gradient } \\
\text { Contour } \\
\text { (LHBGC) }\end{array}$ & $\begin{array}{l}\text { SDUMLA } \\
\text { FV-USM }\end{array}$ & $\begin{array}{l}3816 \\
2952\end{array}$ & $\begin{aligned} & \text { EER } \\
= & 0.0359 \% \\
= & 0.0038 \%\end{aligned}$ & $\begin{array}{l}\text { It handles noise } \\
\text { introduced by } \\
\text { imprecise capture } \\
\text { equipment, signal } \\
\text { distortion, and } \\
\text { individual physical } \\
\text { appearance } \\
\text { fluctuations over time }\end{array}$ & $\begin{array}{l}\text { I treated the noise problem and neglected } \\
\text { other problems such as contrast and blue, } \\
\text { and the second dataset (FV-USM) was not } \\
\text { fully used, but I used one photo session }\end{array}$ \\
\hline $\begin{array}{l}2016 \\
\text { Shirong Q. } \\
\text { et.al., [65] }\end{array}$ & $\begin{array}{l}\text { Dual-Sliding } \\
\text { Window } \\
\text { Localization }\end{array}$ & $\begin{array}{l}\text { SDUMLA } \\
\text { FV-USM } \\
\text { THU }\end{array}$ & & $\begin{array}{l}\mathrm{RR}= \\
97.61 \\
97.02 \\
96.52\end{array}$ & $\begin{array}{l}\text { To eliminate } \\
\text { superfluous data in } \\
\text { finger images and to } \\
\text { minimize disparities }\end{array}$ & $\begin{array}{l}\text { 1. Develop more robust and practical } \\
\text { identification methods to mitigate the } \\
\text { effect of certain factors on the recognition } \\
\text { result in real-world applications, such as } \\
\text { finger position variance, environmental } \\
\text { capture, and endogenous age change } \\
\text { (that is, an image of the same person's } \\
\text { finger vein taken at a different age). Using } \\
\text { a huge training dataset obtained through } \\
\text { data aggregation, we are studying a more } \\
\text { intelligent and economical method for } \\
\text { improving vein determination performance. } \\
\text { 2. The study and creation of a finger vein } \\
\text { classifier to minimize the time required to } \\
\text { determine the reaction time for a large- } \\
\text { scale database using finger vein dilation. } \\
\text { 3. The search for multi-biometric models } \\
\text { (vein (finger vein/palm vein) + fingerprint } \\
\text { (fingerprint/palm print)) incorporates } \\
\text { human-based fusion recognition } \\
\text { technology to enhance the identification } \\
\text { system's performance }\end{array}$ \\
\hline $\begin{array}{l}2017 \\
\text { Nordiana } \\
\text { M. et.al., } \\
\text { [66] }\end{array}$ & $\begin{array}{l}\text { Interval Valued } \\
\text { Fuzzy Sets } \\
\text { K-nearest } \\
\text { Neighbors } \\
\text { (IVFKNN) }\end{array}$ & FV-USM & 2,952 & $\begin{array}{c}A C C= \\
78.1504\end{array}$ & $\begin{array}{c}\text { Allows for the } \\
\text { definition of } \\
\text { membership values } \\
\text { using a lower bound } \\
\text { and an upper bound, } \\
\text { as well as the } \\
\text { interval's length. }\end{array}$ & $\begin{array}{l}\text { You need to use evolution-seeking } \\
\text { approaches to the model as a means } \\
\text { of self-improvement to produce the } \\
\text { parameters necessary to enhance the } \\
\text { accuracy rate }\end{array}$ \\
\hline $\begin{array}{l}2018 \\
\text { Shazeeda } \\
\text { S. et.al., } \\
\text { [67] }\end{array}$ & $\begin{array}{l}\text { Classification } \\
\text { strategies } \\
\text { based on the } \\
\text { Closest Centroid } \\
\text { Neighbor } \\
\text { And Sparse } \\
\text { Representation } \\
\text { (kNCN-SRC) }\end{array}$ & $\begin{array}{l}\text { FV-USM } \\
\text { SDUMLA } \\
\text { HKPU }\end{array}$ & $\begin{array}{l}5904 \\
3816 \\
6,264\end{array}$ & $\begin{array}{l}94.13 \\
66.56 \\
69.52 \\
96.88\end{array}$ & $\begin{array}{l}\text { To improve the } \\
\text { discriminating } \\
\text { rate, the method, } \\
\text { distance, and spatial } \\
\text { distribution are } \\
\text { addressed. }\end{array}$ & $\begin{array}{l}\text { Reconstruction error-based decision- } \\
\text { making is not ideal. Additionally, this } \\
\text { requires experimentation with } k=600 \text { to } \\
\text { attempt to enhance accuracy }\end{array}$ \\
\hline $\begin{array}{l}2019 \\
\text { Shazeeda } \\
\text { S. et.al., } \\
\text { [68] }\end{array}$ & $\begin{array}{l}\text { Sparse } \\
\text { Representation } \\
\text { Classification } \\
\text { (SRC) }\end{array}$ & $\begin{array}{l}\text { FV-USM } \\
\text { SDUMLA } \\
\text { HKPU }\end{array}$ & $\begin{array}{l}5904 \\
3816 \\
6,264\end{array}$ & $\begin{array}{l}95.73 \\
68.08 \\
76.11\end{array}$ & $\begin{array}{l}\text { By categorizing the } \\
\text { test in which the } \\
\text { sample is determined } \\
\text { not only by its sparse } \\
\text { nearest neighbor but } \\
\text { also by the training } \\
\text { sample selection, } \\
\text { the test treats the } \\
\text { sample as its nearest } \\
\text { neighbor (NN). }\end{array}$ & $\begin{array}{l}\text { The extensive testing findings indicated } \\
\text { that no one winner can attain the greatest } \\
\text { performance across all data sets in terms } \\
\text { of classification accuracy and computing } \\
\text { efficiency. Thus, more efficient and } \\
\text { effective methods should be developed } \\
\text { for future study on cross-representation } \\
\text { without sacrificing classification accuracy } \\
\text { compared to other algorithms }\end{array}$ \\
\hline $\begin{array}{l}2020 \\
\text { Dongdong } \\
\text { z. et.al., } \\
\text { [56] }\end{array}$ & $\begin{array}{l}\text { Using } \\
\text { Convolutional } \\
\text { Neural Networks } \\
\text { (CNNs) with } \\
\text { a center loss } \\
\text { function and } \\
\text { dynamic } \\
\text { regulation, we } \\
\text { can define finger } \\
\text { veins } \\
\end{array}$ & $\begin{array}{c}\text { MMCBNU_6000 } \\
\text { FV-USM }\end{array}$ & $\begin{array}{l}6000 \\
2952\end{array}$ & $\begin{array}{l}99.05 \\
97.95\end{array}$ & $\begin{array}{l}\text { Convolutional Neural } \\
\text { Networks (CNNs) } \\
\text { with a center loss } \\
\text { function and dynamic } \\
\text { regulation for the } \\
\text { purpose of defining } \\
\text { finger veins }\end{array}$ & $\begin{array}{l}\text { More persuasive assessment criteria must } \\
\text { be implemented since the parameters must } \\
\text { be optimized because they are assigned to } \\
\text { a random value }\end{array}$ \\
\hline $\begin{array}{l}2021 \\
\text { Bakhtiar A. } \\
\text { et.al., } \\
\text { [50] }\end{array}$ & $\begin{array}{l}\text { Analyses of } \\
\text { the principal } \\
\text { components } \\
\text { and an Adaptive } \\
\text { K-Nearest } \\
\text { Centroid } \\
\text { Neighbour } \\
\text { Classifier }\end{array}$ & FV-USM & 2,952 & 85.64 & $\begin{array}{l}\text { As an upgrade to } \\
\text { the kNCN classifier, } \\
\text { an Adaptive } \\
\text { Centroid Closer } \\
\text { Neighbor (akNCN) is } \\
\text { presented. }\end{array}$ & $\begin{array}{l}\text { In the two experiments at akNCN. .v1 and } \\
\text { akNCN.v2 The accuracy was } 85.64 \text { and } \\
\text { there was no improvement in accuracy } \\
\text { but the time difference was up to } 5,153 \\
\text { seconds for v2 while it was } 6,321 \text { for v1. } \\
\text { The proposed classifier achieves little } \\
\text { classification accuracy compared to the } \\
\text { original kNCN being compared. On Asaha, } \\
\text { on the other hand, a lot of information is } \\
\text { neglected. This method reduces the size } \\
\text { of the training data and removes templates }\end{array}$ \\
\hline
\end{tabular}


algorithms in the main recognition steps for image acquisition were studied, like pre-processing, image enhancement methods, feature extraction, and matching. Pretreatment is an important part of any system, as it largely depends on the state of the data. However, pretreatment and intensive filtering may not always be necessary. Indeed, excessive pre-treatment can lead to undesirable results as some valuable details may be lost in the process, especially when working to extract the features inscribed in the veins. Besides, the traditional feature extraction methods were combined because they provided the best pathological results. Moreover, most studies have focused on the use of local features because they have proven to be much better than holistic approaches. The conventional veins were identified for the matching step. Additionally, because FVR methods are based on machine learning algorithms, machine learning approaches are critical for finding ancient veins. This technology has a high probability of being the focus of future study in this sector. A comparison among different methods for identifying newly developed traditional veins was illustrated. However, deep learning models give a remarkable enhancement compared with the primary vein-recognition models despite the challenges to be solved. The introduction of deep learning approaches to FVR can enhance recognition performance in its broadest sense. Furthermore, some shortcomings of the offered system, the system is more reliable and safer compared to other biometrics methods. While obtaining the image, good image capture requires a system to enhance the qualities of the smaller venous image, wide datasets are required as well. This may help assess all types of FVR technologies.

\section{REFERENCES}

1. Wu J.D., Ye S.H. Driver identification using fingervein patterns with Radon transform and neural network. Expert Syst. Appl. 2009; 36(3): 5793-5799.

2. Yang J., Shi Y., Jia G. Finger-vein image matching based on adaptive curve transformation. Pattern Recognit. 2017; 66: 34-43.

3. Hashimoto J. Finger vein authentication technology and its future. In 2006 Symposium on VLSI Circuits, 2006. Digest of Technical Papers. 2006, 5-8.

4. Wang L., Leedham G., Cho D.S. Minutiae feature analysis for infrared hand vein pattern biometrics. Pattern Recognit. 2008; 41(3): 920-929.
5. Miura N., Nagasaka A., Miyatake T. Extraction of finger-vein patterns using maximum curvature points in image profiles. IEICE Trans. Inf. Syst. 2007; 90(8): 1185-1194.

6. Shahin M., Badawi A., Kamel M. Biometric authentication using fast correlation of near infrared hand vein patterns. Int. J. Biol. Med. Sci. 2007; 2(3): 141-148.

7. Al-Tamimi M S H. A survey on the vein biometric recognition systems: Trends and challenges. Journal of Theoretical and Applied Information Technology, 2019, 97(2), 551-568.

8. Aboalsamh H.A. Vein and fingerprint biometrics authentication-future trends. Int. J. Comput. Commun. 2009; 3(4): 67-75.

9. Wang K., Liu J. Finger vein recognition method based relative distance and angle," Huazhong Keji Daxue Xuebao (Ziran Kexue Ban)/Journal Huazhong Univ. Sci. Technol. Natural Sci. Ed. 2011; 39(5), 96-99. , DOI: 10.5772/18025.

10. Tagkalakis F., Vlachakis D., Megalooikonomou V., Skodras A. A novel approach to finger vein authentication," in 2017 IEEE 14th International Symposium on Biomedical Imaging (ISBI 2017). 2017; 659-662.

11. Lu Y., Wu S., Fang Z., Xiong N., Yoon S., Park D. S.Exploring finger vein based personal authentication for secure IoT. Futur. Gener. Comput. Syst. 2017; 77: 149-160.

12. Sun X., Lin C.Y., Li M.Z., Lin H.W., Chen Q.W., A DSP-based finger vein authentication system," in 2011 Fourth International Conference on Intelligent Computation Technology and Automation. 2011; 2: 333-336.

13. Liu Z., Song S. An embedded real-time fingervein recognition system for mobile devices," IEEE Trans. Consum. Electron. 2012; 58(2): 522-527.

14. Li Z., Nagasaka A., Kurihara T., Kiyomizu H., Kagehiro T. A hybrid biometric system using touch-panel-based finger-vein identification and deformable-registration-based face identification," in 2014 IEEE International Conference on Systems, Man, and Cybernetics (SMC), 2014; 69-74.

15. Khellat-kihel S., Cardoso N., Monteiro J., Benyettou M. Finger vein recognition using Gabor filter and Support Vector Machine," in International image processing, applications and systems conference. 2014; 1-6.

16. Yang L., Yang G., Yin Y., Xiao R. Finger vein image quality evaluation using support vector machines. Opt. Eng. 2013; 52(2): 27003.

17. Finger vein identification using polydirectional local line binary pattern. In 2013 International Conference on ICT Convergence (ICTC). 2013; 61-65.

18. Sapkale M., Rajbhoj S. M. A biometric authentication system based on finger vein recognition," in 
2016 International Conference on Inventive Computation Technologies (ICICT). 2016; 3: 1-4.

19. Wilson C. Vein pattern recognition: a privacy-enhancing biometric. CRC press, 2010.

20. Yang J., Shi Y., Yang J. Personal identification based on finger-vein features," Comput. Human Behav. 2011; 27(5): 1565-1570.

21. Wang K.Q.,. Khisa A.S, Wu X.Q., Zhao Q.S. Finger vein recognition using LBP variance with global matching," in 2012 international conference on wavelet analysis and pattern recognition. 2012; 196-201.

22. Ratha N.K., Govindaraju V. Advances in biometrics: sensors, algorithms and systems. Springer Science \& Business Media, 2007.

23. Matsuda Y., Miura N., Nagasaka A., Kiyomizu H., Miyatake T. Finger-vein authentication based on deformation-tolerant feature-point matching. Mach. Vis. Appl. 2016; 27(2): 237-250.

24. Liu Z., Yin Y., Wang H., Song S., Li Q. Finger vein recognition with manifold learning. J. Netw. Comput. Appl. 2010; 33(3): 275-282.

25. Damavandinejadmonfared S., Mobarakeh A.K., Pashna M., Gou J., Rizi S.M., Nazari S., Khaniabadi S.M., Bagheri M.A. Finger vein recognition using PCA-based methods. World Academy of Science, Engineering and Technology. 2012; 25: 66.

26. Rosdi B.A., Shing C.W., Suandi S.A. Finger vein recognition using local line binary pattern. Sensors. 2011; 11(12): 11357-11371.

27. Meng X., Yang G., Yin Y., Xiao R. Finger vein recognition based on local directional code. Sensors. 2012; 12(11): 14937-14952.

28. Wang H., Du M., Zhou J., Tao L. Weber local descriptors with variable curvature gabor filter for finger vein recognition. IEEE Access. 2019; 12(7): 108261-108277.

29. Song W., Kim T., Kim H.C., Choi J.H., Kong H.J., Lee S.R. A finger-vein verification system using mean curvature. Pattern Recognition Letters. 2011; 32(11): 1541-1547.

30. Kumar A., Zhou Y. Human identification using finger images. IEEE Transactions on image processing. 2011; 21(4): 2228-2244.

31. Liu C., Kim Y.H. An efficient finger-vein extraction algorithm based on random forest regression with efficient local binary patterns. In 2016 IEEE International Conference on Image Processing (ICIP). IEEE 2016, 3141-3145.

32. Davis V., Devane S. Diagnosis of Brain Hemorrhage Using Artificial Neural Network. International Journal of Scientific Research in Network Security and Communication. 2017; 5(1): 20-23.

33. Radzi S.A., Hani M.K., Bakhteri R. Finger-vein biometric identification using convolutional neural network. Turkish Journal of Electrical Engineering \& Computer Sciences. 2016; 24(3): 1863-1878.

34. Tang D., Huang B., Li W., Li X. A method of evolving finger vein template. In2012 International Symposium on Biometrics and Security Technologies. IEEE 2012, 96-101.

35. Xin Y., Liu Z., Zhang H., Zhang H. Finger vein verification system based on sparse representation. Applied optics. 2012; 51(25): 6252-6258.

36. Jagadiswary D., Saraswady D. Biometric authentication using fused multimodal biometric. Procedia Computer Science. 2016; 1(85): 109-116.

37. Yang G., Xi X., Yin Y. Finger vein recognition based on a personalized best bit map. Sensors. 2012; 12(2): 1738-1757.

38. Lu Y., Yoon S., Xie S.J., Yang J., Wang Z., Park D.S. Finger vein recognition using generalized local line binary pattern. KSII Transactions on Internet and Information Systems (TIIS). 2014; 8(5): 1766-1784.

39. Wu J.D., Liu C.T. Finger-vein pattern identification using principal component analysis and the neural network technique. Expert Systems with Applications. 2011; 38(5): 5423-5427.

40. Huang H., Liu S., Zheng H., Ni L., Zhang Y., Li W. DeepVein: Novel finger vein verification methods based on deep convolutional neural networks. In 2017 IEEE International Conference on Identity, Security and Behavior Analysis (ISBA). IEEE 2017, 1-8.

41. Xie C., Kumar A. Finger vein identification using convolutional neural network and supervised discrete hashing. Deep Learning for Biometrics. Springer, Cham. 2017; 109-132.

42. Fang Y., Wu Q., Kang W. A novel finger vein verification system based on two-stream convolutional network learning. Neurocomputing. 2018; 17(290): 100-107.

43. Vega A.P., Travieso C.M., Alonso J.B. Biometric personal identification system based on patterns created by finger veins. In3rd IEEE International Work-Conference on Bioinspired Intelligence, IEEE 2014, 65-70.

44. Vlachos M., Dermatas E. Finger vein segmentation from infrared images based on a modified separable mumford shah model and local entropy thresholding. Computational and mathematical methods in medicine. 2015; 18.

45. Liu H., Song L., Yang G., Yang L., Yin Y. Customized local line binary pattern method for finger vein recognition. InC hinese Conference on Biometric Recognition. Springer, Cham. 2017; 28: 314-323.

46. Park K.R. Finger vein recognition by combining global and local features based on SVM. Computing and Informatics. 2011; 30(2): 295-309. 
47. Wu J.D., Liu C.T. Finger-vein pattern identification using SVM and neural network technique. Expert Systems with Applications. 2011; 38(11): 14284-14289.

48. Veluchamy S., Karlmarx L.R. System for multimodal biometric recognition based on finger knuckle and finger vein using feature-level fusion and k-support vector machine classifier. IET Biometrics. 2017; 6(3): 232-242.

49. Khanam R., Khan R., Ranjan R. Analysis of finger vein feature extraction and recognition using DA and KNN methods. In 2019 Amity international conference on artificial intelligence (AICAI). IEEE 2019, 477-483.

50. Rosdi B.A., Mukahar N., Han N.T. Finger Vein Recognition Using Principle Component Analysis and Adaptive k-Nearest Centroid Neighbor Classifier. International Journal of Integrated Engineering. 2021; 13(1): 177-187.

51. Qin H., El-Yacoubi M.A. Deep representationbased feature extraction and recovering for fingervein verification. IEEE Transactions on Information Forensics and Security. 2017; 12(8): 1816-1829.

52. Qin H., El-Yacoubi M.A. Deep representation for finger-vein image-quality assessment. IEEE Transactions on Circuits and Systems for Video Technology. 2017; 28(8): 1677-1693.

53. Das R., Piciucco E., Maiorana E., Campisi P. Convolutional neural network for finger-veinbased biometric identification. IEEE Transactions on Information Forensics and Security. 2018; 14(2): 360-373.

54. Avc1 A., Kocakulak M., Acrr N. Convolutional Neural Network Designs for Finger-vein-based Biometric Identification. In2019 11th International Conference on Electrical and Electronics Engineering (ELECO) IEEE 2019, 580-584.

55. Scholar A. Minimization of Training Time of a Convolutional Neural Network by Adding K-Neareaset Neighbor as Classifier 1Prof. Souley Boukari; 2Fatima Ahmed Abubakar; 2Atika Ahmad Jibrin; 2Yakubu Nuhu Danjuma; 2020.

56. Zhao D., Ma H., Yang Z., Li J., Tian W. Finger vein recognition based on lightweight $\mathrm{CNN}$ combining center loss and dynamic regularization. Infrared Physics \& Technology. 2020; 105: 103221.

57. Lu Y., Xie S.J., Yoon S., Wang Z., Park D.S. An available database for the research of finger vein recognition. In 2013 6th International congress on image and signal processing (CISP). IEEE 2013; 1: 410-415.

58. Huang B., Dai Y., Li R., Tang D., Li W. Fingervein authentication based on wide line detector and pattern normalization. In 2010 20th international conference on pattern recognition. IEEE 2010, 1269-1272.

59. Yang W., Huang X., Zhou F., Liao Q. Comparative competitive coding for personal identification by using finger vein and finger dorsal texture fusion. Information sciences. 2014; 1(268): 20-32.

60. Asaari M.S., Suandi S.A., Rosdi B.A. Fusion of band limited phase only correlation and width centroid contour distance for finger based biometrics. Expert Systems with Applications. 2014; 41(7): 3367-3382.

61. Ton B.T., Veldhuis R.N. A high quality finger vascular pattern dataset collected using a custom designed capturing device. In 2013 International conference on biometrics (ICB) IEEE 2013, 1-5.

62. Yin Y., Liu L., Sun X. SDUMLA-HMT: a multimodal biometric database," in Chinese Conference on Biometric Recognition, 2011, 260-268.

63. Tome P., Vanoni M., Marcel S. On the vulnerability of finger vein recognition to spoofing. In2014 International Conference of the Biometrics Special Interest Group (BIOSIG) IEEE 2014, 1-10.

64. William A., Ong T.S., Tee C., Goh M.K. Multi-instance finger vein recognition using local hybrid binary gradient contour. In 2015 Asia-Pacific Signal and Information Processing Association Annual Summit and Conference (APSIPA) IEEE 2015, 1226-1231.

65. Qiu S., Liu Y., Zhou Y., Huang J., Nie Y. Fingervein recognition based on dual-sliding window localization and pseudo-elliptical transformer. Expert Systems with Applications. 2016; 1(64): 618-632.

66. Mukahar N., Rosdi B.A. Interval valued fuzzy sets $\mathrm{k}$-nearest neighbors classifier for finger vein recognition. InJournal of Physics: Conference Series. IOP Publishing. 2017; 890(1): 012069.

67. Shazeeda S., Rosdi B.A. Nearest centroid neighbor based sparse representation classification for finger vein recognition. IEEE Access. 2018; 24(7): 5874-5885.

68. Shazeeda S., Rosdi B.A. Finger vein recognition using mutual sparse representation classification. IET Biometrics. 2019; 8(1): 49-58. 